\title{
(6) OPEN ACCESS \\ Is the infant car seat challenge useful? A pilot study in a simulated moving vehicle
}

\author{
Renu Arya, ${ }^{1}$ Georgina Williams, ${ }^{1}$ Anna Kilonback, ${ }^{1}$ Martin Toward, ${ }^{2}$ Michael Griffin, ${ }^{2}$ \\ Peter S Blair, ${ }^{3}$ Peter Fleming ${ }^{3}$
}

- Additional material is published online only. To view please visit the journal online (http://dx.doi.org/10.1136/ archdischild-2016-310730).

${ }^{1}$ Department of Paediatrics, Great Western Hospitals NHS Foundation Trust, Swindon, UK ${ }^{2}$ Institute of Sound and Vibration Research, University of Southampton, Southampton, UK

${ }^{3}$ School of Social and Community Medicine, University of Bristol, Bristol, UK

\section{Correspondence to} Professor Peter Fleming, Department of Child and Adolescent Health, University of Bristol, Bristol, UK; Peter.Fleming@bristol.ac.uk

Received 18 February 2016 Revised 23 June 2016 Accepted 27 June 2016 Published Online First 30 September 2016

\section{ABSTRACT}

Background and objective The American Academy of Pediatrics recommends that preterm infants complete a predischarge 'car seat challenge' observation for cardiorespiratory compromise while in a car seat. This static challenge does not consider the more upright position in a car or the vibration of the seat when the car is moving. This pilot study was designed to assess the cardiorespiratory effects of vibration, mimicking the effect of being in a moving car, on preterm and term infants.

Methods A simulator was designed to reproduce vertical vibration similar to that in a rear-facing car seat at $30 \mathrm{mph}$. 19 healthy newborn term and 21 preterm infants, ready for hospital discharge, underwent cardiorespiratory measurements while lying flat in a cot (baseline), static in the seat $\left(30^{\circ}\right)$, simulator $\left(40^{\circ}\right)$ and during motion (vibration $40^{\circ}$ ).

Results Median test age was 13 days (range 1-65 days) and median weight was $2.5 \mathrm{~kg}$ (IQR: $2.1-3.1 \mathrm{~kg}$ ).

Compared with baseline observations, only the total number of desaturations was significantly increased when infants were placed at $30^{\circ}(p=0.03)$. At $40^{\circ}$, or with vibration, respiratory and heart rates increased and oxygen saturation decreased significantly. Profound desaturations $<85 \%$ significantly increased during motion, regardless of gestational age.

Conclusions This is the first study to assess the effect of motion on infants seated in a car safety seat. Term and preterm infants showed significant signs of potentially adverse cardiorespiratory effects in the upright position at $40^{\circ}$, particularly with simulated motion, not identified in the standard challenge. A larger study is required to investigate the significance of these results.

\section{INTRODUCTION}

Infant car safety seats are used for infants from birth up to $10 \mathrm{~kg}$. They may be too big to effectively secure low-birthweight or preterm infants who are discharged home from neonatal intensive care units (NICUs), at weights of $1.8-2.5 \mathrm{~kg} .{ }^{1}$ In these seats, the prominent occiput of a preterm infant may push the head forward, particularly during sleep, potentially causing airway obstruction. Studies have shown that premature infants are prone to drops in blood oxygen saturation, and apnoea or hypoventilation when restrained in car seats, ${ }^{2-4}$ in up to $60 \%$ of infants studied. ${ }^{5}$ The American Academy of Pediatrics (AAP) recommends that all preterm infants should undergo monitoring in a car seat before discharge-for apnoea, bradycardia or desaturations, ${ }^{67}$ and many UK hospitals follow this advice. The significance and potential impact of these problems is not

\section{What is already known on this topic?}

Some infants seated in car safety seats show signs of cardiorespiratory compromise.

- The infant car seat challenge is used in neonatal units to determine if the infant can travel safely in a car.

- The static challenge does not take into account the more upright position of the seat or the effect of motion when the car is moving.

\section{What this study adds?}

This is the first study to carry out the car seat challenge in a simulated moving car seat.

- Infants showed signs of cardiorespiratory compromise, which were undetected in the static car seat challenge.

- The moving challenge may be a better test to determine if infants can travel safely in a car seat but further research is required.

clear, ${ }^{8}{ }^{9}$ but there have been reports of deaths of infants who have been left in a sitting position, including in car seats-both on journeys, and when parents have used it as an alternative to a pushchair or cot for the infant to sleep in. ${ }^{10-13}$

One survey noted that $94 \%$ of infants, below 5 months of age, spent over $30 \mathrm{~min}$ a day in seating devices including car seats. ${ }^{14}$ The mean was 5.7 \pm 3.5 hours. There have been no studies looking at the effects on infants over such prolonged periods in a sitting position.

There are no universal guidelines on implementing the car seat challenge, ${ }^{15-17}$ and commonly the angle of the back of the car seat to the horizontal is not reported although in a vehicle it should be $40^{\circ}-45^{\circ}$ for maximum protective effect. In our hospital, the challenge is routinely performed with the car seat placed on the floor, using the carrying handle for stability (like many UK units surveyed, see online supplementary appendix 1 ). The angle of the seat's back to the floor is approximately $30^{\circ}$, which is flatter than the position in a vehicle.

No published studies have monitored infants in moving vehicles, so there is no data on whether infants experience more or less cardiorespiratory compromise when travelling. Hence, it is unknown whether the 'car seat challenge' as currently 
performed has any validity as a means of distinguishing between an infant who can safely travel in a car or one who is at risk of adverse effects during such a journey.

\section{STUDY DESIGN AND METHODOLOGY \\ Study aims}

This pilot study investigated the physiological effects on healthy term and preterm infants placed in a static car seat at $30^{\circ}$ and $40^{\circ}$, and whether the motion of a moving vehicle had any adverse or beneficial effects. It replicates the normal routine of a parent preparing and taking their infant on a car journey.

\section{Study design}

Ethical approval was granted. Informed written consent was obtained from both parents of participating infants. Mothers in late pregnancy attending antenatal clinics were informed about the study. Interested mothers of healthy infants were visited 1224 hours after delivery to obtain consent. Given that many term infants were discharged within hours after normal delivery, many infants recruited were delivered by caesarean section. Healthy term or preterm infants on NICU shortly due for discharge were also eligible.

Exclusion criteria included unwell infants, those with known congenital anomalies, cardiorespiratory disease or hypotonia from any cause.

All infants in the study were due to take a similar (nonmonitored) journey home in a car seat within days of the study.

\section{Study protocol}

After random allocation to one of two protocols (to investigate test order), the infants underwent physiological monitoring for $30 \mathrm{~min}$ in a car seat in each of the three positions.

Protocol A:

I. on a horizontal surface, seating angle $30^{\circ}$ (static)

II. on the simulator, seating angle of $40^{\circ}$ (static)

III. on the simulator, seating angle of $40^{\circ}$ with movements to simulate being in a car travelling at $30 \mathrm{mph}$ (motion).

Protocol B:

I. on the simulator, seating angle $40^{\circ}$ (static)

II. on the simulator, seating angle $40^{\circ}$ (in motion)

III. on a horizontal surface, seating angle $30^{\circ}$ (static).

Each of these conditions was compared with baseline-a period before testing when the infant was asleep supine in a cot, for up to 90 min after a feed.

As all infants were due to go home within days of testing, for the $30^{\circ}$ position, the infants' own car seats were used. All infants underwent testing at $40^{\circ}$ in the stationary vibration rig.

The two protocols were designed to determine whether any identified physiological disturbances observed were more likely to be a consequence of being in the car seat, the angle of the car seat or the presence of movement, including identifying any effect from infant sleep state, or the possible effects of being in a car seat for a long period.

\section{Motion simulator}

A motion simulator was developed to reproduce vertical vibration broadly representative of that at the base of a car safety seat fixed in a rear-facing position in the back seat of a small family car (see figure 1 and online supplementary video 1 ). The angle of fixation was approximately $40^{\circ}$ to the horizontal, using the standard Isofix system. The simulator was designed, manufactured and tested by the Human Factors Research Unit within the Institute of Sound and Vibration Research at the University of Southampton and received ethical approval for use in neonates. The simulator reproduced the vertical vibrations from travelling at $30 \mathrm{mph}$ on a straight urban road, excluding braking, acceleration or going over bumps (see online supplementary appendix 2).

\section{Infant monitoring}

Physiological recordings were made using a 'capnocheck' recording system (Oxi-pulse sleep capnograph, Pulmolink UK) allowing continuous recording of inspiratory and expiratory carbon dioxide levels $\left(\mathrm{EtCO}_{2}\right)$, oxygen saturation $\left(\mathrm{SpO}_{2}\right)$, respiratory rate (RR) and heart rate (HR), sampled at $1 \mathrm{~s}$ intervals. The monitor has an artefact rejection programme designed to cope with movement. All infants were constantly observed by an experienced neonatal nurse and/or doctor. A report was generated for each infant in each position using the PROFOX Respiratory Oximetry Software.

If any significant episodes of apnoea (more than $15 \mathrm{~s}$ ) or oxygen desaturation ( $<85 \%$ for more than $20 \mathrm{~s}$ ) were observed, the test was immediately stopped. These pragmatic cut-offs were chosen to minimise responses to minor, artefactual or selflimiting apnoea or desaturation while ensuring a prompt response to more significant episodes and minimising any risk to the infant. Resuscitation equipment and trained personnel were available immediately.

\section{Statistical analyses}

In this pilot study, we aimed to recruit 20 term and 20 preterm infants. No studies in a vibrating car seat have been conducted; hence, the nature, frequency and magnitude of any adverse effects were unknown. The sample size was pragmatic, by each infant acting as his/her own control (ie, each being studied in each condition-static and moving), and this should generate CIs for potential discernible treatment effects to help inform a larger study. It is unknown whether the movement of a simulated car journey would make such effects more or less likely or severe.

The sampled values for all parameters were imported into an Excel spreadsheet, and all analyses were conducted using SPSS V.23.

The mean values obtained in each condition for each infant for $\mathrm{SpO}_{2}, \mathrm{EtCO}_{2}, \mathrm{HR}$ and $\mathrm{RR}$ were used as point estimates (ie, as single-value units of interest). Given the small numbers and skewed nature of the data a non-parametric approach was

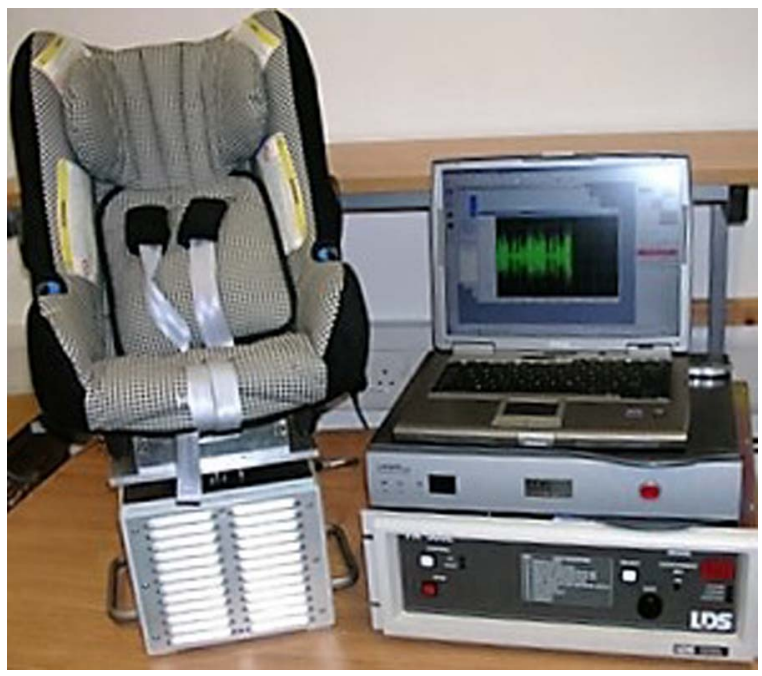

Figure 1 Car seat motion simulator with controls. 


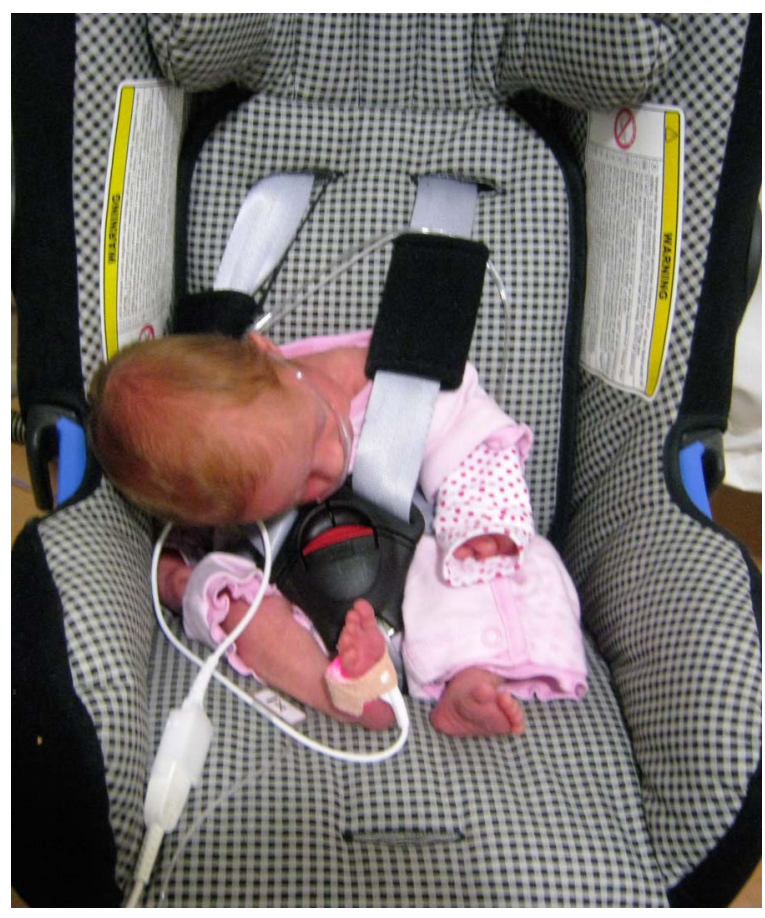

Figure 2 One preterm infant who flopped forward during 'motion'. used for the paired data (Wilcoxon test). The McNemar's test was used for categorical paired data. For looking at differences in test order the Mann-Whitney and $\chi^{2}$ tests were used. Every infant was to undergo three study positions randomly assigned as per protocol and data from each study were compared with the baseline observation period in the cot.

Similar comparisons were made for the frequency and duration of dips in saturation (a fall in $\mathrm{SpO}_{2} \geq 4 \%$ lasting for $\geq 10 \mathrm{~s}$ and $\mathrm{SpO}_{2}$ below $85 \%$ for at least $4 \mathrm{~s}$ ), episodes of apnoea (pauses of $>10 \mathrm{~s}$ ) and bradycardia $(<100 \mathrm{bpm}$ in preterms, $<60 \mathrm{bpm}$ in term infants).

\section{RESULTS}

Infant demographics

Forty infants were studied; 21 preterm (53\%) and 22 were male (55\%). The median gestational age was 36 weeks (IQR: 31-39 weeks), ranging from 27 weeks 5 days to 41 weeks 5 days. The median birth weight was $2.5 \mathrm{~kg}$ (IQR: $1.5-3.2 \mathrm{~kg}$ ) ranging from 0.8 to $4.8 \mathrm{~kg}$. Seventeen infants were born by normal vaginal delivery $(42.5 \%), 10$ by elective $(25.0 \%)$ and 13 by emergency caesarean section $(32.5 \%)$.

\section{Data at testing}

The median age at testing was 13 days (IQR: 6-33 days) ranging from 1 day after birth to 65 days. Preterm or very lowbirthweight infants were tested when they were mature enough

\begin{tabular}{|c|c|c|c|c|c|}
\hline Outcome variable & Position & $\mathbf{N}$ & Median & IQR & p Value* \\
\hline Heart rate $(\mathrm{bpm})$ & $\begin{array}{l}\text { At rest in cot } \\
30^{\circ} \\
40^{\circ} \\
\text { In motion }\end{array}$ & $\begin{array}{l}39 \\
36 \\
39 \\
37\end{array}$ & $\begin{array}{l}145 \\
143.5 \\
150 \\
150\end{array}$ & $\begin{array}{l}127-155 \\
126.5-156.8 \\
135-158 \\
129-157.5\end{array}$ & $\begin{array}{l}\text { Ref group } \\
0.69 \\
0.01 \\
0.047\end{array}$ \\
\hline Oxygen saturation (\%) & $\begin{array}{l}\text { At rest in cot } \\
30^{\circ} \\
40^{\circ} \\
\text { In motion }\end{array}$ & $\begin{array}{l}39 \\
36 \\
39 \\
37\end{array}$ & $\begin{array}{l}96 \\
94.5 \\
94 \\
93\end{array}$ & $\begin{array}{l}93-97 \\
93-96 \\
92-96 \\
91-95\end{array}$ & $\begin{array}{l}\text { Ref group } \\
0.42 \\
0.03 \\
0.0003\end{array}$ \\
\hline Number of desaturations $<85 \%$ in $30 \mathrm{~min}(\mathrm{n})$ & $\begin{array}{l}\text { At rest in cot } \\
30^{\circ} \\
40^{\circ} \\
\text { In motion }\end{array}$ & $\begin{array}{l}39 \\
36 \\
38 \\
35\end{array}$ & $\begin{array}{l}1 \\
3 \\
4 \\
6\end{array}$ & $\begin{array}{l}0-7 \\
0.3-7 \\
0-6 \\
1-11\end{array}$ & $\begin{array}{l}\text { Ref group } \\
0.12 \\
0.17 \\
0.001\end{array}$ \\
\hline $\begin{array}{l}\text { Total number of desaturations ( } \mathrm{n} \text { ) } \\
\text { (fall in } \mathrm{SpO}_{2} \geq 4 \% \text { lasting for } \geq 10 \text { s per hour) }\end{array}$ & $\begin{array}{l}\text { At rest in cot } \\
30^{\circ} \\
40^{\circ} \\
\text { In motion }\end{array}$ & $\begin{array}{l}39 \\
36 \\
39 \\
36\end{array}$ & $\begin{array}{l}26 \\
33 \\
32 \\
39\end{array}$ & $\begin{array}{l}19-36 \\
22-41 \\
24-37 \\
28-46\end{array}$ & $\begin{array}{l}\text { Ref group } \\
0.03 \\
0.005 \\
<0.0001\end{array}$ \\
\hline Respiratory rate (breaths per minute) & $\begin{array}{l}\text { At rest in cot } \\
30^{\circ} \\
40^{\circ} \\
\text { In motion }\end{array}$ & $\begin{array}{l}38 \\
35 \\
38 \\
36\end{array}$ & $\begin{array}{l}42 \\
45 \\
48 \\
46.5\end{array}$ & $\begin{array}{l}39-50 \\
39-49 \\
38.8-55 \\
41-50.8\end{array}$ & $\begin{array}{l}\text { Ref group } \\
0.12 \\
0.0004 \\
0.009\end{array}$ \\
\hline End-tidal $\mathrm{CO}_{2}(\mathrm{kPa})$ & $\begin{array}{l}\text { At rest in cot } \\
30^{\circ} \\
40^{\circ} \\
\text { In motion }\end{array}$ & $\begin{array}{l}38 \\
35 \\
38 \\
36\end{array}$ & $\begin{array}{l}4.58 \\
4.56 \\
4.61 \\
4.65\end{array}$ & $\begin{array}{l}3.99-5.13 \\
3.88-5.07 \\
4.13-5.08 \\
4.20-5.14\end{array}$ & $\begin{array}{l}\text { Ref group } \\
0.84 \\
0.32 \\
0.38\end{array}$ \\
\hline Outcome variable & Position & $\mathrm{N}$ & n & Per cent & $p$ Value $\dagger$ \\
\hline One or more bradycardias $(\mathrm{n})$ & $\begin{array}{l}\text { At rest in cot } \\
30^{\circ} \\
40^{\circ} \\
\text { In motion }\end{array}$ & $\begin{array}{l}39 \\
36 \\
39 \\
37\end{array}$ & $\begin{array}{l}4 \\
2 \\
2 \\
3\end{array}$ & $\begin{array}{l}10.3 \\
5.6 \\
5.2 \\
8.1\end{array}$ & $\begin{array}{l}\text { Ref group } \\
0.62 \\
0.62 \\
0.68\end{array}$ \\
\hline One or more apnoeas $(n)$ & $\begin{array}{l}\text { At rest in cot } \\
30^{\circ} \\
40^{\circ} \\
\text { In motion }\end{array}$ & $\begin{array}{l}39 \\
36 \\
39 \\
37\end{array}$ & $\begin{array}{l}6 \\
1 \\
2 \\
0\end{array}$ & $\begin{array}{l}15.4 \\
2.8 \\
5.1 \\
0\end{array}$ & $\begin{array}{l}\text { Ref group } \\
0.13 \\
0.45 \\
0.13\end{array}$ \\
\hline
\end{tabular}


for discharge. The postmenstrual age at testing ranged from 34 weeks 3 days to 42 weeks 4 days. The median weight was $2.5 \mathrm{~kg}$ (IQR: $2.1-3.1 \mathrm{~kg}$ ) ranging from 1.6 to $4.8 \mathrm{~kg}$.

We aimed to test each infant in each condition for $30 \mathrm{~min}$ but interruptions from infant care procedures meant that the actual times varied and not all tests were completed in a few cases. The baseline recordings with the infant placed supine in a cot ranged from 17 to $120 \mathrm{~min}$ with a median of $60 \mathrm{~min}$; thus, the results were adjusted to a standard $30 \mathrm{~min}$ or per unit of time tested.

Many infants put their chin on their chest during testing but three infants slumped forward during vibration (see figure 2). Their position was left while they maintained normal oxygen saturations to observe what would happen. They lifted their head up briefly at intervals but could not maintain this position.

\section{Outcome for all infants}

Table 1 shows the outcomes for all infants comparing measurements at rest in the cot (reference group) with the three other positions. The only significant difference in the outcome variables comparing baseline to the $30^{\circ}$ position was a higher number of total desaturations at $30^{\circ}$.

However, infants in the static $40^{\circ}$ position and in motion had significantly higher $\mathrm{HR}$ and $\mathrm{RR}$, lower $\mathrm{SpO}_{2}$ and more total desaturations, compared with baseline. In motion, episodes of desaturation $<85 \%$ were also significantly increased, a median of six episodes versus one when at rest. Episodes of bradycardia and apnoea were slightly but not significantly more common at rest. $\mathrm{EtCO}_{2}$ level rose slightly but non-significantly at $40^{\circ}$ and in motion.

\section{Term versus preterm}

Preterm infants were older at testing (median 25 days, range 7-65 days) compared with term infants (median 6 days, range 1-15 days).

Table 2 shows the same outcomes as in table 1 but for term infants only. The numbers are smaller, hence the potential for significance is reduced, but the direction of the differences persisted and was similar in term and preterm infants.

Term infants placed in the static $40^{\circ}$ position had significantly higher $\mathrm{HR}$ and $\mathrm{RR}$ and lower $\mathrm{SpO}_{2}$. In motion, the increased HR did not reach significance compared with baseline but the $\mathrm{RR}$ was significantly higher, the $\mathrm{SpO}_{2}$ significantly lower and the number of desaturations was increased.

Table 3 shows the same outcomes as in table 1 but for preterm infants only. The differences are in the same direction but slightly less marked compared with term infants.

In comparison with term infants baseline HRs were much higher, and although the rates increased sequentially when the infants were seated at $30^{\circ}, 40^{\circ}$ and in motion these differences were not statistically significant compared with baseline. The median $\mathrm{SpO}_{2}$ dropped from baseline but was only significant

Table 2 Outcome for term infants

\begin{tabular}{|c|c|c|c|c|c|}
\hline Outcome variable & Position & $\mathrm{N}$ & Median & IQR & p Value* \\
\hline Heart rate $(\mathrm{bpm})$ & $\begin{array}{l}\text { At rest in cot } \\
30^{\circ} \\
40^{\circ} \\
\text { In motion }\end{array}$ & $\begin{array}{l}19 \\
18 \\
19 \\
18\end{array}$ & $\begin{array}{l}127 \\
127 \\
138 \\
131\end{array}$ & $\begin{array}{l}116-149 \\
115.3-142.8 \\
126-144 \\
123.5-143.8\end{array}$ & $\begin{array}{l}\text { Ref group } \\
0.65 \\
0.03 \\
0.16\end{array}$ \\
\hline Oxygen saturation (\%) & $\begin{array}{l}\text { At rest in cot } \\
30^{\circ} \\
40^{\circ} \\
\text { In motion }\end{array}$ & $\begin{array}{l}19 \\
18 \\
19 \\
18\end{array}$ & $\begin{array}{l}95 \\
93.5 \\
94 \\
93\end{array}$ & $\begin{array}{l}92-97 \\
93-95.3 \\
91-96 \\
91-95\end{array}$ & $\begin{array}{l}\text { Ref group } \\
0.11 \\
0.04 \\
0.01\end{array}$ \\
\hline Number of desaturations $<85 \%$ in 30 min (n) & $\begin{array}{l}\text { At rest in cot } \\
30^{\circ} \\
40^{\circ} \\
\text { In motion }\end{array}$ & $\begin{array}{l}19 \\
18 \\
19 \\
17\end{array}$ & $\begin{array}{l}1 \\
2.5 \\
4 \\
2\end{array}$ & $\begin{array}{l}0.5-1.5 \\
0-6.5 \\
0-7 \\
0.5-8\end{array}$ & $\begin{array}{l}\text { Ref group } \\
0.06 \\
0.06 \\
0.04\end{array}$ \\
\hline $\begin{array}{l}\text { Total number of desaturations ( } \mathrm{n} \text { ) } \\
\text { (fall in } \mathrm{SpO}_{2} \geq 4 \% \text { lasting for } \geq 10 \text { s per hour) }\end{array}$ & $\begin{array}{l}\text { At rest in cot } \\
30^{\circ} \\
40^{\circ} \\
\text { In motion }\end{array}$ & $\begin{array}{l}19 \\
18 \\
19 \\
17\end{array}$ & $\begin{array}{l}25 \\
31 \\
31 \\
35\end{array}$ & $\begin{array}{l}13-36 \\
22-42 \\
23-36 \\
24-45\end{array}$ & $\begin{array}{l}\text { Ref group } \\
0.08 \\
0.049 \\
0.01\end{array}$ \\
\hline Respiratory rate (breaths per minute) & $\begin{array}{l}\text { At rest in cot } \\
30^{\circ} \\
40^{\circ} \\
\text { In motion }\end{array}$ & $\begin{array}{l}18 \\
17 \\
18 \\
17\end{array}$ & $\begin{array}{l}43 \\
47 \\
51 \\
49\end{array}$ & $\begin{array}{l}37.5-52.3 \\
37.5-52 \\
39.8-56.3 \\
39.5-55\end{array}$ & $\begin{array}{l}\text { Ref group } \\
0.28 \\
0.009 \\
0.02\end{array}$ \\
\hline End-tidal $\mathrm{CO}_{2}(\mathrm{kPa})$ & $\begin{array}{l}\text { At rest in cot } \\
30^{\circ} \\
40^{\circ} \\
\text { In motion }\end{array}$ & $\begin{array}{l}18 \\
17 \\
18 \\
17\end{array}$ & $\begin{array}{l}4.25 \\
4.51 \\
4.47 \\
4.21\end{array}$ & $\begin{array}{l}3.72-4.73 \\
3.81-4.88 \\
3.79-5.11 \\
3.73-5.09\end{array}$ & $\begin{array}{l}\text { Ref group } \\
0.55 \\
0.15 \\
0.38\end{array}$ \\
\hline Outcome variable & Position & $\mathbf{N}$ & $\mathrm{N}$ & Per cent & p Valuet \\
\hline One or more bradycardias (n) & $\begin{array}{l}\text { At rest in cot } \\
30^{\circ} \\
40^{\circ} \\
\text { In motion }\end{array}$ & $\begin{array}{l}19 \\
18 \\
19 \\
18\end{array}$ & $\begin{array}{l}3 \\
1 \\
2 \\
3\end{array}$ & $\begin{array}{l}15.8 \\
5.6 \\
10.6 \\
16.7\end{array}$ & $\begin{array}{l}\text { Ref group } \\
0.48 \\
1.00 \\
1.00\end{array}$ \\
\hline One or more apnoeas (n) & $\begin{array}{l}\text { At rest in cot } \\
30^{\circ} \\
40^{\circ} \\
\text { In motion }\end{array}$ & $\begin{array}{l}19 \\
18 \\
19 \\
18\end{array}$ & $\begin{array}{l}3 \\
1 \\
0 \\
0\end{array}$ & $\begin{array}{l}15.8 \\
5.6 \\
0 \\
0\end{array}$ & $\begin{array}{l}\text { Ref group } \\
0.62 \\
0.25 \\
0.25\end{array}$ \\
\hline
\end{tabular}


Table 3 Outcome for preterm infants

\begin{tabular}{|c|c|c|c|c|c|}
\hline Outcome variable & Position & $\mathbf{N}$ & Median & IQR & p Value* \\
\hline Heart rate $(\mathrm{bpm})$ & $\begin{array}{l}\text { At rest in cot } \\
30^{\circ} \\
40^{\circ} \\
\text { In motion }\end{array}$ & $\begin{array}{l}20 \\
18 \\
20 \\
19\end{array}$ & $\begin{array}{l}151.5 \\
153 \\
156 \\
157\end{array}$ & $\begin{array}{l}145-159 \\
143.8-158.2 \\
150.3-158 \\
150-163\end{array}$ & $\begin{array}{l}\text { Ref group } \\
0.88 \\
0.20 \\
0.21\end{array}$ \\
\hline Oxygen saturation (\%) & $\begin{array}{l}\text { At rest in cot } \\
30^{\circ} \\
40^{\circ} \\
\text { In motion }\end{array}$ & $\begin{array}{l}20 \\
18 \\
20 \\
19\end{array}$ & $\begin{array}{l}96 \\
96 \\
94.5 \\
94\end{array}$ & $\begin{array}{l}93-97 \\
93.5-97.3 \\
94-96 \\
91-95\end{array}$ & $\begin{array}{l}\text { Ref group } \\
0.71 \\
0.34 \\
0.01\end{array}$ \\
\hline Number of desaturations $<85 \%$ in 30 min (n) & $\begin{array}{l}\text { At rest in cot } \\
30^{\circ} \\
40^{\circ} \\
\text { In motion }\end{array}$ & $\begin{array}{l}20 \\
18 \\
19 \\
18\end{array}$ & $\begin{array}{l}5 \\
3 \\
4 \\
7.5\end{array}$ & $\begin{array}{l}0-8 \\
1-8.25 \\
2-6 \\
1.8-14.3\end{array}$ & $\begin{array}{l}\text { Ref group } \\
0.69 \\
0.85 \\
0.02\end{array}$ \\
\hline Total number of desaturations (n) & $\begin{array}{l}\text { At rest in cot } \\
30^{\circ} \\
40^{\circ} \\
\text { In motion }\end{array}$ & $\begin{array}{l}20 \\
18 \\
20 \\
19\end{array}$ & $\begin{array}{l}28 \\
33 \\
34 \\
38\end{array}$ & $\begin{array}{l}22-36 \\
23-41 \\
25-37 \\
36-51\end{array}$ & $\begin{array}{l}\text { Ref group } \\
0.21 \\
0.07 \\
0.001\end{array}$ \\
\hline Respiratory rate (breaths per minute) & $\begin{array}{l}\text { At rest in cot } \\
30^{\circ} \\
40^{\circ} \\
\text { In motion }\end{array}$ & $\begin{array}{l}20 \\
18 \\
20 \\
19\end{array}$ & $\begin{array}{l}42 \\
44 \\
48 \\
45\end{array}$ & $\begin{array}{l}40-48.8 \\
38-49.3 \\
37-53 \\
41-48\end{array}$ & $\begin{array}{l}\text { Ref group } \\
0.42 \\
0.02 \\
0.45\end{array}$ \\
\hline End-tidal $\mathrm{CO}_{2}(\mathrm{kPa})$ & $\begin{array}{l}\text { At rest in cot } \\
30^{\circ} \\
40^{\circ} \\
\text { In motion }\end{array}$ & $\begin{array}{l}19 \\
18 \\
20 \\
19\end{array}$ & $\begin{array}{l}4.99 \\
4.67 \\
4.71 \\
4.79\end{array}$ & $\begin{array}{l}4.18-5.5 \\
4.05-5.19 \\
4.23-5.22 \\
4.60-5.14\end{array}$ & $\begin{array}{l}\text { Ref group } \\
0.36 \\
0.85 \\
0.68\end{array}$ \\
\hline Outcome variable & Position & $\mathrm{N}$ & $\mathbf{n}$ & Per cent & p Valuet \\
\hline One or more bradycardias ( $\mathrm{n}$ ) & $\begin{array}{l}\text { At rest in cot } \\
30^{\circ} \\
40^{\circ} \\
\text { In motion }\end{array}$ & $\begin{array}{l}20 \\
18 \\
20 \\
19\end{array}$ & $\begin{array}{l}1 \\
1 \\
0 \\
0\end{array}$ & $\begin{array}{l}5.0 \\
5.6 \\
0 \\
0\end{array}$ & $\begin{array}{l}\text { Ref group } \\
0.48 \\
1.00 \\
1.00\end{array}$ \\
\hline One or more apnoeas (n) & $\begin{array}{l}\text { At rest in cot } \\
30^{\circ} \\
40^{\circ} \\
\text { In motion }\end{array}$ & $\begin{array}{l}20 \\
18 \\
20 \\
19\end{array}$ & $\begin{array}{l}3 \\
0 \\
2 \\
0\end{array}$ & $\begin{array}{l}15 \\
0 \\
10 \\
0\end{array}$ & $\begin{array}{l}\text { Ref group } \\
0.25 \\
0.62 \\
1.00\end{array}$ \\
\hline
\end{tabular}

during motion. The number of desaturations was much higher among preterm infants (5) at baseline and rose significantly during motion. RR showed a significant increase at $40^{\circ}$ but not when in motion. $\mathrm{EtCO}_{2}$ levels were higher in all positions, with fewer bradycardic events and a similar number of apnoeic events, but no significant differences between positions.

The order of testing did not affect the results.

\section{DISCUSSION}

This is the first study of its kind looking at the physiological cardiorespiratory response in infants seated in a moving car seat.

We have shown that the simulation rig is safe to use and identified physiological disturbances not seen under static conditions in many infants. It may thus be a more accurate predictor of potential cardiorespiratory risk compared with the standard car seat challenge.

The finding that significant potentially adverse physiological effects were more frequent when the infant was at $40^{\circ}$ and in motion than when at $30^{\circ}$ regardless of which test came first suggests that it is the more upright position and the addition of movement that is responsible rather than an effect of a prolonged period in the sitting position.

We tested infants for up to $30 \mathrm{~min}$ - a relatively short journey time; however, some had frequent (up to 16) significant desaturations $(<85 \%$ for $\geq 4 \mathrm{~s})$ during this time. The vibration test reproduced motion in a straight line-no bumps, turns, braking or acceleration, so this probably underestimates the effect of travelling on real roads. Previous studies of infants in static car seats have noted that cardiorespiratory problems increase in frequency with longer periods in a car seat. ${ }^{1} 18$

All infants in our study were healthy but the effects in infants with cardiorespiratory disease or hypotonia may be more marked, as has been shown in the static car seat challenge. ${ }^{19}$

The low muscle tone and prominent occiput of preterm infants may lead to neck flexion and possible airway obstruction when in a car seat, ${ }^{20}$ and this may be exacerbated by motion. Some preterm infants with recurrent desaturations flopped forward in an extremely flexed position during motion, raising their heads intermittently but could not maintain a raised head position. The head and shoulders came forward despite shoulder straps, which may be too long for smaller infants allowing some forward movement. ${ }^{2}$ While head supports with cut-outs over the occipital area have been shown to reduce neck flexion, ${ }^{21}$ further research using them during motion is indicated. Parents often leave their infant alone in the back seat when travelling, and on long journeys the infant may slump forward in this way, resulting in respiratory compromise. Our findings suggest that it may be beneficial on a long journey for an adult to sit with the infant in the back of the car or use a mirror to observe the infant's position. 
This small-scale pilot study was designed to identify any potential adverse effects of a more upright position and of motion on infants in car seats. Limitations are its small size, lack of randomisation of the infants studied, the lack of formal sleep state monitoring and the limited time each infant spent in a car seat.

We have shown potential changes in cardiorespiratory stability during periods in which the infant is in a more upright position than usually used in static car seat challenges, and the exacerbation of these effects during simulated movement in some infants. We cannot be certain of the clinical significance or potential risks posed by the changes we have identified, which could be a consequence of position, restraint, movement or a combination of all three. The infants in the supine position were not restrained (as they would be in a car bed); thus, we cannot assess the effects of restraint in this position.

More research is needed to quantify these effects, and to investigate how best to avoid them if they are clinically significant. In particular, there is a need for larger studies to investigate the effect of increasing infant age (and thus size), and duration of journey time, together with simulating the effects of changes in vehicle speed and direction.

The importance of protecting infants in the event of a moving vehicle accident must be emphasised, and infant car seats must be used whenever infants travel in cars (as per UK law), ${ }^{22}{ }^{23}$ but these findings support the AAP guideline that infant car seats should not be used as a routine infant sleep environment. $^{24}$

\section{CONCLUSIONS}

This is a unique pilot study - the first to look at the physiological effect of vibration on infants in a car safety seat. The standard static car seat challenge currently used in hospitals does not reflect the angle or motion of the journey undertaken by the infant. The infant, in a seat placed at the more upright $40^{\circ}$ position plus vibration experienced in a car, shows significantly increased $\mathrm{HR}, \mathrm{RR}$ and decreased $\mathrm{SpO}_{2}$. Simulating motion reveals a striking increase in potentially clinically significant oxygen desaturations. Surprisingly these differences were similar in term and preterm infants.

The motion simulator offers the possibility of further investigation of the potential benefits and limitations of various designs of infant car seats. This may lead to a revision of current recommendations for testing infants' suitability for travel in an infant car seat and also have implications for the design of car seats for newborn infants.

Acknowledgements Thanks to the nursing staff (particularly SN Rebecca Thomas and SN Joanne Newell) at the Great Western Hospitals NHS Trust NICU for their help in carrying out the car seat challenges. Video clip courtesy of Matthew Hill and BBC Points West.

Contributors RA conceived and designed the study, obtained ethical approval and funding and performed data analysis. MT and MG designed and built the vibration simulator and obtained ethical approval for its use. AK, GW and RA participated in the enrolment of patients, performing the challenges and data collection. PF contributed to the design of the study with technical advice plus data analysis. PB undertook the statistical analysis. RA, PF and PB wrote the paper with critical revision from all authors.

Funding Supported by a grant from the Lullaby Trust (formerly the Foundation of the Study of Infant Deaths) project number 259.
Competing interests None declared.

Patient consent Parental/guardian consent obtained.

Ethics approval Approval was obtained from West of England Research Ethics Committee (no. 11/h0106/1) and from Southampton University Human Experimentation Safety and Ethics Committee for the safety and use of the vibration simulator in humans.

Provenance and peer review Not commissioned; externally peer reviewed.

Open Access This is an Open Access article distributed in accordance with the Creative Commons Attribution Non Commercial (CC BY-NC 4.0) license, which permits others to distribute, remix, adapt, build upon this work non-commercially, and license their derivative works on different terms, provided the original work is properly cited and the use is non-commercial. See: http://creativecommons.org/ licenses/by-nc/4.0/

\section{REFERENCES}

1 Merchant JR, Worwa C, Porter $\mathrm{S}$, et al. Respiratory instability of term and near-term healthy newborn infants in car safety seats. Pediatrics 2001;108:647-52.

2 Bull MJ, Stroup KB. Premature infants in car seats. Pediatrics 1985;75:336-9.

3 Willett LD, Leuschen MP, Nelson LS, et al. Ventilatory changes in convalescent infants positioned in car seats. J Pediatr 1989;115:451-5.

4 Mullen D, Coutts J. Monitoring premature babies in car seats: the car seat challenge. JNN 2002;8:129-31.

5 Davis NL. Screening for cardiopulmonary events in neonates: a review of the infant car seat challenge. J Perinatol 2015;35:235-40.

6 American Academy of Pediatrics Committee on Accident and Poison Prevention. Safe transportation of premature infants. Pediatrics 1991;87:120-2.

7 Bull MJ, Engle WA, Committee on Injury, Violence, and Poison Prevention and Committee on Fetus and Newborn; American Academy of Pediatrics. Safe transportation of preterm and low birth weight infants at hospital discharge. Pediatrics 2009:123:1424-9.

8 Southall DP, Richards JM, Rhoden KJ, et al. Prolonged apnea and cardiac arrhythmias in infants discharged from neonatal intensive care units: failure to predict an increased risk for sudden infant death syndrome. Pediatrics 1982;70:844-51.

9 Pilley E, McGuire W. Pre-discharge "car seat challenge" for preventing morbidity and mortality in preterm infants. Cochrane Database Syst Rev 2006;(1):CD005386.

10 Fleming PJ, Blair PS. Sudden unexpected deaths after discharge from the neonatal intensive care unit. Semin Neonatol 2003;8:159-67.

11 Côté A, Bairam A, Deschenes $M$, et al. Sudden infant deaths in sitting devices. Arch Dis Child 2008;93:384-9.

12 Tonkin SL, Vogel SA, Bennet $L$, et al. Apparently life threatening events in infant car safety seats. BMJ 2006;333:1205-6.

13 Bamber AR, Pryce J, Ashworth MT, et al. Sudden unexpected infant deaths associated with car seats. Forensic Sci Med Pathol 2014;10:187-92.

14 Callahan CW, Sisler C. Use of seating devices in infants too young to sit. Arch Pediatr Adolesc Med 1997;151:233-5.

15 Williams LE, Martin JE. Car seat challenges: where are we in implementation of these programs? J Perinat Neonatal Nurs 2003;17:158-63.

16 Joffe $\mathrm{N}$, Hall J. Limiting the risks of apnoea and bradycardia in low birth weight infants using car seats. JNN 2006;12:91-6.

17 Davis NL, Zenchenko $Y$, Lever $A$, et al. Car seat safety for preterm neonates: implementation and testing parameters of the infant car seat challenge. Acad Pediat 2013;13:272-7

18 Salhab WA, Khattak A, Tyson JE, et al. Car seat or car bed for very low birth weight infants at discharge home. J Pediatr 2007;150:224-8.

19 Bass JL, Mehta KA. Oxygen desaturation of selected term infants in car seats. Pediatrics 1995;96(pt 1):288-90

20 Tonkin SL, Mclntosh CG, Hadden W, et al. Simple car seat insert to prevent upper airway narrowing in preterm infants: a pilot study. Pediatrics 2003;112:907-13.

21 McIntosh CG, Tonkin SL, Gunn AJ. Randomized controlled trial of a car safety seat insert to reduce hypoxia in term infants. Pediatrics 2013;132:326-31.

22 http://www.childcarseats.org.uk/the-law/ (accessed 10 Aug 2015).

23 Rice $T$, Anderson $C$. The effectiveness of child restraint systems for children aged 3 years or younger during motor vehicle collisions: 1996 to 2005. Am J Public Health 2009:99:252-7.

24 Safe transportation of premature and low birth weight infants. American Academy of Pediatrics. Committee on Injury and Poison Prevention and Committee on Fetus and Newborn. Pediatrics 1996;97:758-60. 